\title{
Development and Evaluation of Modules in Technical Writing
}

\author{
Ma. Theresa B. Nardo ${ }^{1, *}$, Esther R. Hufana² \\ ${ }^{1}$ General Education Department, Tarlac College of Agriculture, Camiling, Tarlac, Philippines \\ ${ }^{2}$ College of Arts and Sciences, Benguet State Univsity, Baguio City, Philippines \\ *Corresponding author: misty_jet@yahoo.com
}

Received December 11, 2013; Revised April 28, 2014; Accepted May 15, 2014

\begin{abstract}
This study focused on the development and evaluation of Technical Writing modules to develop autonomous learning among students. The modules were based on the needs such as special techniques in technical writing, constructing verbal to non-verbal data, writing conclusions from research findings, writing recommendations for research, stating research problems, among others. Module II was evaluated along subject matter, vocabulary and structures, exercises, illustrations, and physical make-up. Module II was rated "Good" by the control (2.94) and experimental (3.12) students. The English teachers rated the modules "Excellent". The modules were evaluated fit for the curriculum, for the students and for the teachers and were recommended for use in the Technical Writing class. Researches of similar nature of the study may be conducted to validate the findings of the study.
\end{abstract}

\section{Keywords: module development, modular instruction, evaluation, technical writing}

Cite This Article: Ma. Theresa B. Nardo, and Esther R. Hufana, "Development and Evaluation of Modules in Technical Writing." American Journal of Educational Research, vol. 2, no. 6 (2014): 341-350. doi: 10.12691/education-2-6-2.

\section{Introduction}

There are teachers' activities outside the school which decrease the quality time for students to learn the language. Various activities and quasi teaching concerns like attendance to seminars, workshops and trainings lessen teachers' time in the classroom. Lessons are not delivered as planned because of interruptions beyond the control of the teacher.

The English proficiency of Filipino students is continually declining over the years as shown in the low performance in national assessment in their competency in the use of the English language. Students have great difficulty in expressing their ideas in the classroom and in writing which could also be attributed to the utter neglect of developing the writing competencies of the students. Classroom activities are neglected or are not enough to help the students develop their writing competence.

Students have writing problems in expressing themselves systematically and logically [9]. This lack of skills as one of the most common complaints students have when they encounter a particularly difficult assignment may be an outcome of neglecting one's studies for a considerable period of time, poor education or something else.

The questions on writing difficulty of learners have become the focus of some researchers. However, the problem remains unsolved. There are three reasons why so many children and youth find writing difficult like composing text is a complex and difficult undertaking that requires the deployment and coordination of multiple affective, cognitive, linguistic, and physical operations to accomplish goals associated with genre-specific conventions, audience needs, and author's communicative purposes [13]. Another, many students today, who come from impoverished homes, speak a second language. The teachers are facing a higher proportion of students who struggle not only in composing, but also with basic writing skills. On the other hand, say that many teachers feel ill-equipped to handle these competing pressures because they lack the prerequisite pedagogical knowledge, instructional capabilities, and valued resources for teaching writing, and in part because writing curricula, which exert a strong influence on teachers' writing instruction, tend to be underdeveloped and misaligned with other curricula. Third, the quality of instruction students receive is a major determinant of their writing achievement [16].

The development of the writing skills of second language learners has become the focus of teachers who have seen the need to strengthen the writing for academic purposes. Curriculum designers and textbook writers recognized the need to provide for second language students the necessary materials that allow the writing class to assume an equal role with other language skills [19].

The use of modules is an alternative instructional design for the learning and satisfaction of the students. The students work on their own and the teacher's role is to guide and monitor the progress of the students in doing 
their individual tasks. With the use of the modules, students work on various activities that are interesting and challenging enough to maintain focus and attention [3].

The use of modules also encourages independent study. It directs students to practice or rehearse information. To gain mastery of the concepts, exercises are given following the progression of activities from easy to difficult. The arrangement of the exercises as such formalizes the level of difficulty that the learners can perform. Another benefit of using modules for instruction is the acquisition of a better self-study or learning skills among students. Students engage themselves in learning concepts presented in the module. They develop a sense of responsibility in accomplishing the tasks provided in the module. With little or no assistance from the teacher, the learners progress on their own. They are learning how to learn; they are empowered.

\subsection{Theoretical Framework}

\subsubsection{Development of Instructional Materials}

One of the important components within the curriculum is the language teaching material which is often the most tangible and visible aspect of teaching-learning process. For the goals of education to be achieved, the syllabus defines activities that run through the language classroom. Moreover, language learning is more meaningful with the linguistic and experiential content because of instructional materials that give detailed specifications of content. Instructional materials direct teachers to attain the goals and objectives of a specific language content or pedagogical tasks. It is contended [20] that instructional material can help define goals of the syllabus, and the roles of teachers and learners within the instructional process.

Instructional materials for the classroom are the products of practical reason and purposeful imagination. They are the outputs of insights and desire to address the needs of the learners. Materials should meet the needs and satisfy the interests, temper the attitudes, and preferences of the learners for whom they are made. If the main purpose in language teaching is enabling the learners become communicatively competent in the target language, which is English, there is a need for new kinds of language teaching materials. Below is the model used in the development of materials [5].

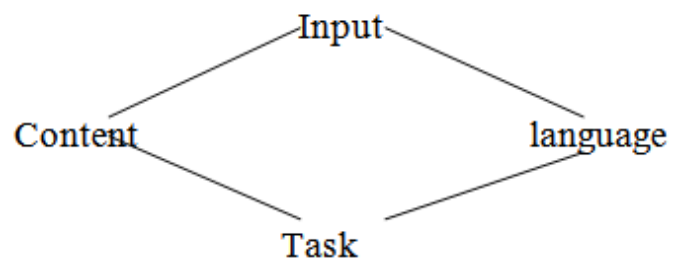

Figure 1. Materials Design Model (Hutchinson and Waters, 1987)

A coherent framework for a varied and creative model in designing instructional materials [5] was used.

This model has four elements: input, content focus, language focus and task. The input may be a text, diagram, a gadget, a picture or any piece of communication depending upon the needs analyzed. The input prepares the students to use the materials for activities, learn new language items, and follow correct models for language use, and be able to present ideas on any topic for writing. These prior activities allow learners to use the knowledge they already know about the language and the lesson in class.

The content conveys information and feelings about something while the language focus provides opportunity for the analysis and synthesis of language use, i.e. to take the language to pieces, to study how it works, and to practice putting them together. The task on hand enables the learners to use the content and language knowledge built up through the unit. The language and content are drawn from the input and are selected according to what the learners will need to do the task.

Communicative task is defined as a piece of classroom work which involves learners in comprehending, manipulating, producing or interacting in the target language [12].

Further, seven (7) principles which can serve as guidelines in designing materials are given [11]. 1) Materials should be clearly linked to the curriculum they serve. Materials and activities should be chosen on the basis of their relevance to the objectives and goals of the curriculum. 2. Materials should be authentic in terms of text and tasks. 3. Text refers to the authenticity of the input data which are used as point of departure in materials development. Task authenticity refers to what learners actually do in relation to the input data. Learners are asked to undertake tasks which replicate or rehearse their communicative behaviors. 4. Materials should stimulate interaction. Materials should stir interaction among learners. Materials must cause the conversation among interlocutors for them to negotiate meaning, interpret signs and symbols or understand dialogs. 5. Materials should allow learners to focus on the formal aspect of the language. There is evidence that learners can benefit from form-focused activities that require them to solve problems, form and perform hypothesis, come to conclusions and construct their own rules from instances and examples of language use. 6. Materials should encourage learners to develop learning skills and skills in learning-how-to-learn. Research on learning styles and work in learner-centered curriculum development has led to the trend of incorporating into materials activities that teach students about learning as it is impossible to teach everything students need to know in class. Hence, it is necessary to provide learners with efficient learning strategies, develop skills in self-evaluation, assist them to set their own objectives and develop skills needed to negotiate the curriculum; 7. Materials should encourage learners to apply their developing language skills to the world beyond the classroom. That a good language learner who always looks for opportunities to do must be made a part of the materials. Many learners fail to make connections between language work done in class and the language they encounter outside. Tasks designed to get learners to apply their skills need to be elaborated.

A material such as a module enables the learner to have a control over his learning. It is a set of learning opportunities that is organized around well-defined topic which contains the elements of instructions, specific objectives, teaching-learning activities and evaluation using criteria-referenced measurement.

\subsection{Statement of the Problem}


The study was conducted to develop and evaluate modules in technical writing.

Specifically, it sought to answer the following questions: 1. What are the technical writing needs of students in technical writing? 2. What modules are to be developed based on the writing needs of the students? 3. How do the control group and the experimental group differ in their evaluation of the modules along: a. subject matter; b. vocabulary and structures; c. exercises; d. illustrations; and e. physical make-up. 4.a How do the English teachers differ in their evaluation of the modules in terms of a. subject matter; b. vocabulary and structures; c. exercises; d. illustrations; and e. physical make-up. 4.b How do the English teachers differ in their evaluation of fit along: a. curriculum; b. students; and c. teachers.

\subsection{Hypotheses of the Study}

1. There is a significant difference in the evaluation of the control and experiment groups along the stated criteria (subject matter, vocabulary and structures, exercises, illustrations and physical make-up). 2. There is a significant difference in the evaluation of modules among the English teachers along: a) the five criteria (subject matter, vocabulary and structures, exercises, illustrations, and physical make-up) and b) the evaluation of fit (curriculum, students and teacher).

\section{Methodology}

\subsection{Research Design}

This study used the descriptive method in the development and evaluation of modules in Technical Writing. Before the development of the modules, a survey on the writing needs of the students was conducted. The results of the needs analysis became the basis of developing the modules. Upon identifying the needs, the lessons were grouped according to content designed for a whole term. The topics were divided into three: overview of technical writing, special techniques in technical writing and writing the research paper. The first set of needs was used in developing the overview of Technical Writing (Module I) as background. The special techniques in technical writing (Module II) Module III was on the fundamentals of research writing needs of the students.

The modules were evaluated by English teachers who teach technical writing from six State Universities and Colleges (SUCs) from Cordillera Administrative Region (CAR), Regions 1, 2 and 3. The corrections and suggestions of the students as well as the teachers were integrated in the modules.

\subsection{Population and Locale of the Study}

The study was conducted at Tarlac College of Agriculture. Six teacher-respondents from Abra State Institute of Science and Technology (ASSIST), and Benguet State University (BSU) to represent CAR; Don Mariano Marcos State University (DMMSU) to represent Region 1; Isabela State University to represent Region II; Pampanga Agricultural College (PAC) and Tarlac College of Agriculture (TCA) to represent Region III were chosen based on the years of teaching technical writing.
The student-respondents consisted of two groups: the control group and the experimental group enrolled in the technical writing course. The control group used the module during the regular class period. On the other hand, the experiment group was met by the teacher once a week to orient and to follow up the progress of the students in their work and to give further instructions as needed.

\subsection{Data Collection Procedure}

Before the data were collected, a letter of permission to conduct the study was forwarded to the Presidents of each State University/College where the English teacherrespondents are employed and to the dean/s where the students in the Technical Writing classes were officially enrolled.

The questionnaires for needs analysis and evaluation of materials were submitted to the members of the panel for evaluation. Suggestions and comments for improvement were integrated in the final instruments. The needs analysis questionnaire contained items on vocabulary building, sentence revision, completion of data, transposing verbal data to non-verbal data. Writing some parts of the research paper was also part of the questionnaire.

\subsection{Data Collection Instrument}

The data collection instruments that were used were the questionnaires that were distributed to the respondents of the study both the English teachers and the Technical Writing students under the experimental and control groups.

The evaluation instrument used by the English teachers and control group and students in the experimental group was a modified checklist for evaluating modules [10]. It was modified to suit the local needs of the students. The instrument covered five criteria for evaluating the materials - a) subject matter; b) vocabulary and structures; c) exercises; d) illustrations; and e) physical make-up. The ratings from the scale of 0 to 4 with 0 described as Totally Lacking; 1 - Weak; 2 -Adequate; 3 - Good; and 4 Excellent. The test of the fit was also part of the evaluation. The test of fit between the modules and the curriculum, the students and the teachers [10].

\subsection{Treatment of Data}

To determine the pressing writing needs of the students, ranking and frequency counts were used based on the results of the actual test that the students took up. Descriptive method was used to describe the evaluation of the students and the teachers on the modules along the set criteria for the materials. The evaluation of fit of the modules between the curriculum, the students and the teachers used the descriptive method.

\section{Results and Discussion}

\section{Technical Writing Needs of the Students}

In this section of the study, the writing needs of Technical Writing students were identified according to their perceived technical writing needs and their actual level of competence in working on technical writing tasks. 
The first part described the perceived competencies of the mechanics and content of technical writing. The identified needs were marked $\mathrm{Y}$ (yes), S (sometimes) and $\mathrm{N}$ (never). The other part was the actual writing tasks that they worked on.

Table 1 shows the perceived technical writing needs of the students according to difficulty. Eight of the perceived most pressing technical writing needs that ranked 4.5 were explaining a mechanism, illustrating a process, conceptualizing a problem, proposing recommendation from research findings, stating measurable research objectives, differentiating the features of technical reports and writing the abstract. These needs were related to the special techniques of technical writing such as explaining a mechanism and illustration of a process. Explaining a mechanism pertains to the writing ability of presenting the manner of how a mechanism works or explaining the system that completes a mechanism. Likewise, illustration of a process is a technique that shows the steps to be followed in completing a process. The technical writing skill for illustrating a process categorically presents the stages to complete a whole process. For the students to rank these as some of the highest perceived needs means that they have no idea on how to explain a mechanism and how to illustrate a process.

Table 1. Perceived Technical Writing Needs of the Students

\begin{tabular}{|c|c|c|c|c|}
\hline \multirow{2}{*}{ No } & Table 1. Perceived Technical Writing Needs of the Students \\
\cline { 2 - 5 } & $\begin{array}{c}\text { Technical Writing } \\
\text { Skill Areas }\end{array}$ \\
\hline 1 & I can explain a mechanism. & 10 & $\mathrm{~S}$ & Rank \\
\hline 2 & I can illustrate a process. & 10 & $\mathrm{~S}$ & 4.5 \\
\hline 3 & I can conceptualize a problem. & 10 & $\mathrm{~S}$ & 4.5 \\
\hline 4 & I can collate research data. & 10 & $\mathrm{~S}$ & 4.5 \\
\hline 5 & $\begin{array}{c}\text { I can propose recommendations from } \\
\text { research findings }\end{array}$ & 10 & $\mathrm{~S}$ & 4.5 \\
\hline 6 & I can state measurable objectives. & 10 & $\mathrm{~S}$ & 4.5 \\
\hline 7 & $\begin{array}{c}\text { I can differentiate the features of } \\
\text { technical reports. }\end{array}$ & 10 & $\mathrm{~S}$ & 4.5 \\
\hline 8 & I can compose an abstract. & 10 & $\mathrm{~S}$ & 4.5 \\
\hline 9 & $\begin{array}{c}\text { I can identify a social research from a } \\
\text { technical research. }\end{array}$ & 9 & $\mathrm{~S}$ & 10.5 \\
\hline 10 & $\begin{array}{c}\text { I am conscious of mechanics } \\
\text { (punctuations, capitalization ). }\end{array}$ & 9 & $\mathrm{~S}$ & 10.5 \\
\hline 11 & I can distinguish an opinion from a fact. & 9 & $\mathrm{~S}$ & 10.5 \\
\hline 12 & $\begin{array}{c}\text { I can qualify claims based on gathered } \\
\text { data. }\end{array}$ & 9 & $\mathrm{~S}$ & 10.5 \\
\hline 13 & $\begin{array}{c}\text { I can transpose verbal data to non- } \\
\text { verbal materials and vice versa. }\end{array}$ & 6 & $\mathrm{~S}$ & 14.5 \\
\hline 14 & $\begin{array}{c}\text { I can define technical terms in my own } \\
\text { words. }\end{array}$ & 8 & $\mathrm{~S}$ & 14.5 \\
\hline 15 & $\begin{array}{c}\text { I can interpret graphic presentations } \\
\text { such as graphs and charts. }\end{array}$ & 8 & $\mathrm{~S}$ & 14.5 \\
\hline 16 & $\begin{array}{c}\text { I can derive conclusions from research } \\
\text { findings. }\end{array}$ & 8 & $\mathrm{~S}$ & 14.5 \\
\hline 17 & I can spot errors in a technical paper. \\
\hline 18 & $\begin{array}{c}\text { I know the different parts of a research } \\
\text { paper. }\end{array}$ & 7 & $\mathrm{~S}$ & 17.5 \\
\hline 19 & $\begin{array}{c}\text { I can analyze content of technical } \\
\text { reports }\end{array}$ & 6 & $\mathrm{~S}$ & 20 \\
\hline 20 & $\begin{array}{c}\text { I can recognize classification of terms } \\
\text { according to methods and functions. }\end{array}$ & 6 & $\mathrm{~S}$ & 20 \\
\hline 21 & $\begin{array}{c}\text { I can identify topic sentence in a } \\
\text { paragraph. }\end{array}$ & 6 & $\mathrm{~S}$ & 20 \\
\hline 22 & $\begin{array}{c}\text { I can note differences and similarities of } \\
\text { information. }\end{array}$ & 5 & $\mathrm{~S}$ & 22 \\
\hline 23 & $\begin{array}{c}\text { I can distinguish the sentence pattern } \\
\text { for technical writing. }\end{array}$ & 3 & $\mathrm{~S}$ & 23 \\
\hline & Grand Mean & 8.21 & & 17.5 \\
\hline Sometimes Y-Yes & & & \\
\hline
\end{tabular}

of the students (4.5) relate with the research writing needs like conceptualization of a research problem, collating research data, proposing recommendations from research findings, stating measurable objectives, differentiating the features of technical reports and composing an abstract. The research process and all writing related activities were identified as some of the most difficult perceived needs of the students. With regard to research writing skill, the students can sometimes conceptualize a problem. However, the problems they presented were not stated in the manner research questions should be stated. This could be attributed to their lack of exposure to what a research paper is and research writing yet. Although they claimed that they can state measurable objectives, the objectives that they wrote did not observe the basic requirements of researchable objectives. In terms of their ability to write recommendations from research findings, they could hardly put words together as recommendation based on data that were presented in tables. Moreover, they were not able to translate the presented research findings into tables. The students had no way to explain in words what were seen in tables or graphs. Furthermore, the students perceived that it was difficult for them to collate research data. This means that they did not have the experience in collating research data yet. One of the difficult tasks perceived by the students was to compose an abstract. Although they claimed that they could recommend from research findings, this was rated sometimes. The result shows that the research skills of the students are inadequate.

In view of the above, the needs analysis is a powerful tool that helps clarify and validate true needs [7]. It enables educators and practitioners to shape the curriculum development that based the content of language courses on the communication needs, wants and interests of the learners.

The table also shows the other writing needs of the students which were ranked 10.5. They were not conscious of mechanics such as punctuations and capitalization. The paragraph that was given in the survey did not have punctuation marks. The unpunctuated paragraph was barely marked by the respondents which shows that the students were not conscious of using punctuations in sentences and in the paragraph. Some of the respondents, however, used punctuations where they were needed.

With regard to distinguishing opinion from fact, most of the respondents sometimes can distinguish a fact from an opinion which could be attributed to the students' inadequate experiences in performing the tasks. Also, most of the students had no idea of justifying claims of research findings. Interpretation and substantiation of research outputs are unfamiliar to them due to the lack of experience in research writing. The table also shows that the respondents did not transpose verbal data to nonverbal materials. This means that they had difficulty in interpreting data in a given table; and they did not attempt to translate the text of the given result into a table. This further shows that the students need guidance in interpreting research.

A special technique in technical writing that the students needed is definition of technical terms which ranked 14.5. The words that were given in the questionnaire were not defined technically. The complete parts of definition such as term, genus and differentia were not present in almost all the words that they defined. A 
combination of the term and the differentia was most evident in the result.

The interpretation of graphic presentations such as graphs and charts was also ranked 14.5 and the students' ability to derive conclusions from research findings ranked likewise. These results reveal that the students could sometimes interpret graphical presentations. Likewise, the students could give conclusions from research findings sometimes.

The students also needed to spot errors in a technical paper and to know the different parts of a research paper which were ranked 17.5. Since some of the students were conscious of sentence construction, a few of them needed to learn how to identify the errors in sentences. Technical writing skills include the ability to edit or rewrite faulty sentences to obtain coherence or clarity of ideas presented. Moreover, the respondents ranked the knowledge of the different parts of the research paper, 17.5. This means that some of them sometimes knew the parts of the research paper.

Skills that the respondents claimed to have been the easier ones to do were analyze content of technical reports, recognize classification of terms according to methods and functions, and identify topic sentences in a paragraph; all these three ranked 20. On noting differences and similarities of information, very few of the respondents experienced difficulty with it because it was ranked 22 . This goes to show that most of the respondents readily identified the similarities and differences of information given them. For the least need that was identified by the students was distinguishing sentence patterns for technical writing. The students could distinguish the sentences that were technically crafted. This means that the sentences that were straightforward and were short and direct to the point were understood by the students.

All the perceived needs of the students were rated "Sometimes" with a grand mean of 8.21.

The identified needs became the bases in the development of modules. In like manner [5], needs analysis must be the starting point for devising syllabuses, courses, materials and the kind of teaching and learning that takes place and that implicit in needs analysis is the requirement for fact-finding or the collection of data.

\subsection{Results of Writing Tasks}

The second part of the needs assessment questionnaire was a set of activities that the respondents actually worked on. Seven (7) out of the 11 writing skills were ranked 4 (Table 2).

Table 2 presents the most difficult tasks by the students which involved the special techniques in technical writing like description of a process, description of a mechanism and definition, revising weak be-verbs and sentence pattern for technical writing, revising noun stacks, revising redundant phrasing, constructing verbal to nonverbal data, writing conclusions from research findings and writing recommendations for research. These needs were identified as the most difficult skills for the students and ranked 4. All the respondents did not answer the items on these areas. For description of a process, description of a mechanism and definition of technical terms, the students could not describe a process nor describe a mechanism because they did not describe the given process nor the mechanism. They did not attempt to define the technical terms correctly. There were some respondents who gave informal definitions by the $\mathrm{A}=\mathrm{C}$ pattern, the term and the differentia.

Revising weak be-verbs (rank 4) and revising noun stacks were also ranked 4 . The result shows that the students lacked the necessary skill in rewriting sentences. Noun stacks are those structures which use more than one noun altogether such that the sentence becomes overstuffed with nouns. These nouns can be deleted to observe brevity.

Redundant phrasing (rank 4) is one of the top difficulties as shown in the actual writing result of the students. It was noted that technical writing presupposes the use of simple words and exact terms to convey ideas and information more readily to the intended audience of a report. In the test, the students could not give shorter terms. In technical writing, verbosity is done away with, thus, unnecessary words in a phrase may be deleted as in the near future in which near could be deleted.

Transfer of information from verbal to non-verbal data ranked 4. Constructing verbal to non-verbal data allows a reader of a technical report to understand the information that the writer wishes to convey. Transforming verbal to non-verbal data is a useful skill in technical writing. Results, however, show that the students could not translate verbal data to non-verbal data. This means that the data that were presented in tables were not explained in a written form.

Considered one of the most pressing problems of the students is to write conclusions from research findings. Results show that the respondents did not come up with a write up of a given research data. The respondents also did not have any idea on how to write recommendations. These were the identified most pressing needs of the students because they have not been exposed to research writing yet and their knowledge and skills were limited.

Differentiating opinions from facts ranked 8 . Differentiating facts from opinions is important on matters that concern objectivity. Mechanics ranked 9 which means that most of the students punctuated the paragraph correctly.

As regards writing research problems derived from the given situations, the students failed to form real research problems. The last item that the students considered the least in their writing needs is sentence construction which includes arranging words in normal order, putting main idea first, and using correct pronoun reference. The results reveal that there were sentences that the students reconstructed correctly although more attention such as the consistent use of the pronoun and its reference and arranging words in the normal order be given. This is in consonance [19] with the findings that said that the students' limited competence on sentence unity particularly errors on run-on sentences and choppy sentences. Further, the study on the writing proficiency level of freshman students of BSBT College [1] disclosed that students wrote overload sentences as well as fragments. For students to have established their proficiency in writing sentences not in writing paragraphs [6]. She said that it has been observed that teaching English focused on sentence construction which is the traditional way of teaching employed by traditional English teachers. 
These needs were identified to guide the development of the modules. The result of the study affirms the findings that before and during the course, the learner's needs can be identified by the learners themselves thus, the teaching methods would depend on the resources[13]. With the current study, the development of modules was used to address the identified needs of the students.

Table 2. Result of Actual Technical Writing Needs

Table 2. Result of Actual Technical Writing Needs
\begin{tabular}{|c|c|c|c|}
\hline No & f & Rank \\
\hline 1 & Special techniques in Technical Writing & 20 & 5.5 \\
\hline 2 & Description of a process & 20 & 5.5 \\
\hline 3 & Description of a mechanism & 20 & 5.5 \\
\hline 4 & Definition & 20 & 5.5 \\
\hline 5 & Revising weak be-verbs/sentence pattern for & 20 & 5.5 \\
\hline 6 & Technical Writing & 20 & 5.5 \\
\hline 7 & Revising noun stacks & 20 & 5.5 \\
\hline 8 & Revising redundant phrasing & 20 & 5.5 \\
\hline 9 & Writing conclusions from research findings & 20 & 5.5 \\
\hline 10 & Writing recommendations for research & 10 & 5.5 \\
\hline
\end{tabular}

\subsection{Modules to address the technical writing needs}

Module I contains the linguistic features and introductory technical writing concepts consisting of 11 regular tasks, 5 assigned tasks and 3 evaluative tasks. The learning content contains the linguistic features, and sixteen (16) tasks in Module I.

Special techniques and concepts in technical writing consisted of 17 regular tasks, 15 assigned tasks and 7 evaluative tasks were taken up in Module II.

Module III, on the other hand, were on research writing concepts. These were incorporated in 18 regular tasks, 6 assigned tasks and 4 evaluative tasks.

These modules were developed based on the identified writing needs of the students to enhance their technical writing skills and to strengthen learner autonomy. With the use of the modules, the students are trained to learn how to learn, with the supervision of the teacher to ensure that the students learn correctly [3].

\subsection{Students' Evaluation on Module II}

This portion presents the summary of the evaluation of the different aspects of Module II by the experimental and control groups.

Table 3 shows the evaluation of the subject matter. The control had a mean score of 2.94 (G) while the experimental group garnered a mean score of 3.12 (G) which is slightly higher than the control. There is no significant difference in the evaluation of the subject matter by the two groups, statistically.

For vocabulary and structures, a mean of 2.87 (Good) was registered by the experimental group while the control group had a mean of 2.99 (Good). Although the control group had higher rating, statistical analysis showed no significant difference.

Table 3 shows that the exercises were rated G (Good) by the experimental (3.07) and control (3.11). The results of the evaluation of the exercises had no significant difference with a mean difference of. 02275 which signifies that the exercises in
Module II developed comprehension and tested knowledge of main ideas, details and sequence of ideas.

The illustrations were rated $\mathrm{G}$ (Good) by the control (2.84) and experimental (3.06) which is higher. This yielded a mean difference of -.13606 which is not significant.

Table 3. Summary of Evaluation by the Students

\begin{tabular}{|c|c|c|c|c|}
\hline Categories & $\mathrm{E}$ & $\mathrm{C}$ & $\mathrm{MD}$ & $\mathrm{D}$ \\
\hline Subject Matter & $3.12(\mathrm{G})$ & $2.94(\mathrm{G})$ & $0.18 \mathrm{~ns}$ & $\mathrm{G}$ \\
\hline $\begin{array}{c}\text { Vocabulary and } \\
\text { Structures }\end{array}$ & $2.87(\mathrm{G})$ & $2.99(\mathrm{G})$ & $-0.12 \mathrm{~ns}$ & $\mathrm{G}$ \\
\hline Exercises & $3.07(\mathrm{G})$ & $3.11(\mathrm{G})$ & $-0.04 \mathrm{~ns}$ & $\mathrm{G}$ \\
\hline Illustrations & $2.84(\mathrm{G})$ & $3.06(\mathrm{G})$ & $-0.22^{*}$ & $\mathrm{G}$ \\
\hline Physical make-up & $2.55(\mathrm{G})$ & $3.07(\mathrm{G})$ & $-0.52^{*}$ & $\mathrm{G}$ \\
\hline Grand Mean & $2.89(\mathrm{G})$ & $3.03(\mathrm{G})$ & $-0.144 \mathrm{~ns}$ & $\mathrm{G}$ \\
\hline
\end{tabular}

Legend: ${ }^{\text {ns }}$ - no significant difference $*$ - significant difference

Illustrations are useful in the learning process of the students because the students learn faster when they see things that support their processing of information. This result is in consonance with a research finding [17] visual materials for visual types of students were prepared.

Table 3 also presents that the physical make-up of the Module II was rated by the control (3.07) and experimental (2.55) which is lower compared to the control. No significant difference, however, was noted.

In general, the module was evaluated "Good" with the grand means of 2.89 (experimental) and 3.02 (control).

\subsection{Evaluation of Modules by English Teachers}

This section presents the evaluation of the modules along five (5) categories: subject matter, vocabulary and structures, exercises, illustrations and physical make-up. Each category had qualifying statements by which the evaluators based their evaluation of the modules. They had to choose from a scale of 5 with 5 as the highest which best describes the part of the module they evaluated.

The researcher used the checklists for textbook evaluation, teacher's manual and evaluation of the fit of the materials [10] and were modified to fit local situation. The evaluation of fit refers to the fitness of materials along curriculum, students and teachers.

\subsection{Evaluation of the Modules by the English Teachers}

This section presents the overall evaluation of the English teachers of the three modules in terms of subject matter, vocabulary and structures, exercises, illustrations and physical make-up.

Table 4. Summary of Evaluation of the Modules by the English Teachers

\begin{tabular}{|c|c|c|c|c|c|}
\hline Categories & Mean & Scores & \multicolumn{3}{|c|}{} \\
\hline & I & II & III & MD & D \\
\hline Subject Matter & 3.87 & 3.75 & 3.67 & 3.76 & E \\
\hline Vocabulary and Structures & 3.83 & 3.59 & 3.65 & 3.69 & E \\
\hline Exercises & 3.63 & 3.47 & 3.57 & 3.55 & E \\
\hline Illustrations & 3.44 & 3.22 & 3.33 & 3.33 & E \\
\hline Physical make-up & 3.11 & 3.17 & 3.22 & 3.16 & G \\
\hline Grand Mean & 3.57 & 3.44 & 3.49 & 3.50 & E \\
\hline
\end{tabular}

Legend: ${ }^{\text {ns }}$ - no significant difference * - significant difference 
Subject Matter. Table 4 shows the teacherrespondents' rating on the subject matter that are covered in the modules. Module I got the highest mean score of 3.88 (Excellent) followed by Module II (3.75) which is considered excellent and Module III (3.67) also excellent. The overall mean for subject matter is 3.76 (Excellent).

Vocabulary and Structures. For vocabulary and structures, Module I got the highest mean of 3.83 which is excellent and is followed by Module III (3.65) which is also excellent and Module II got 3.59 also excellent. The overall mean for vocabulary and structures is 3.69 (Excellent).

Exercises. Teachers' rating for exercises are as follows: Module I 3.63 which is excellent and is followed by Module III (3.57) which is excellent and Module II (3.47) also excellent. The overall mean for exercises is 3.56 (Excellent).

Illustrations. The table shows the teachers' rating on illustrations. Module I got 3.44 which is excellent followed by Module III (3.33) also excellent and Module II (3.17) which is good. The overall mean for illustrations is 3.33 which is excellent.

Physical make-up. Teacher-respondents' rating on physical make-up are as follows: Module III (3.22) which is excellent, Module II (3.17) which is good and Module I (3.11) which is good. The overall mean for physical makeup is 3.16 which is good.

The result of the evaluation as depicted in the table shows that Module I got the highest rating of 3.57 (Excellent) followed by Module III with 3.49 (Excellent), and Module II with a grand mean of 3.44 (Excellent).

Some experts commented that "the topics included in each unit were carefully selected to address the needs of Filipino students of Technical Writing"; and "The lessons are arranged from simple to complex tasks. There are also several, varied tasks that can make the students handle and complete their work." The evaluator experts [4] said that "The tasks are varied and well-organized; teachers would have an easier time to adjust the activities to the level of the learners."

Two kinds of expert reviews [15] are (1) those focusing on the content of instruction and (2) those focusing on delivery of methods. Expert reviews focusing on content are expert with respect to instructional content. They ensure that instructional design expert who may not be well versed in the specialized subject matter is consistent with current or desire work methods or state-of-the-art thinking on the subject matter. With the help of the expert review, instructional materials prepared are assured of timeliness, accuracy and credibility.

Expert review are indentified experts from inside or outside the organization by the help of key management conduct survey or evaluation. Another approach is to ask experienced instructors or tutors to review an instructional package. If the materials designed are intended for individualized, learner-paced delivery, the material is tried out.

A checklist [15] that is helpful in revising and improving the instructional package was used. The expert review considers the following points for evaluation: 1) the instructional objectives for completeness, sequence and priority, 2) the clarity with which those characteristics are described or used, 3) the match between objectives and materials, 4) the condition whether the instructional package is adequate for delivery in an individualized or group format and whether it reflects the latest thinking on the topic, 5) the sequence of instructional events within each part of the instructional package, and 6) the suggestions for revision.

\subsection{Test of Fit of the Modules}

Instructional materials are chosen according to their usefulness and relevance to the learning process thereby considering important issues that respond to the qualifications of worthwhile materials [10]. The points to be addressed in the system of material evaluation are the fit between the materials and the curriculum, the students and the teachers.

The curriculum is the basis for developing instructional materials. Materials are developed in consonance with curricular guidelines and to evaluate the fit of the modules to the curriculum. The selection of materials must lend to the attainment of the goals of the curriculum and supplement the activities that the language program prepares.

The table that follows shows the fit between the modules and the curriculum, the students and the teachers.

Evaluation of fit between the Modules and the Curriculum. Table 5 shows the evaluation of the English teachers on the test of fit between the modules and the curriculum. Item 1 on the module is a good fit for the curriculum was given a rate of 4 in the 3 modules. Item 2 was rated 3.83 in Module I, 3.83 in Module II and 3.67 in Module III. The overall mean for item 2 is 3.78 .

As regards thematic content (item 3) this was rated 3.83 in the 3 modules having a grand mean of 3.83. The result implies that the lessons were developed according to theme such that the flow of the lessons and the topics of the lessons were related. A previous lesson was a basis for the preceding ones.

The module fits the pedagogical and Second Language Acquisition (SLA) philosophy of the course (item 4) was given 4 for Module I and II and 3.83 for Module III. The grand mean is 3.94 .

In this context [10], it is emphasized that materials should be clearly linked to the curriculum they serve. Materials and activities should be chosen on the basis of their relevance to the objectives and goals of the curriculum.

Test of Fit between Modules and the Students. The table shows the evaluation of the English teachers on the test of fit between the modules and the students.

Table 5 presents that the explanations were understandable and usable for the students (item 1) got 4 (Yes-A good fit) from all the teachers. The result conveys that the explanations about the topics about the characteristics of technical writing and the basic principles of good writing were understandable and useful for the students.

Students was rated 3.83 for Module I and 4 for Modules II and III, respectively with a grand mean of 3.94. For the students to comprehend the topics, there adequate examples that demonstrated the concepts.

The activities were appropriate (item 3) was rated 4 (Yes-A good fit) for Module I and 3.83 for both Module II and III by all the teachers. The result implies that the activities in the modules were suitable for the students. 
The concepts that were presented were deepened by the tasks that the students worked on. It means further that the exposure of the students to appropriate activities heightened their understanding. The grand mean for this item is 3.89 .

Table 5. Evaluation of the test fit between the modules and the curriculum, the students and the teachers

\begin{tabular}{|c|c|c|c|c|}
\hline & & & & \\
\hline $\begin{array}{l}\text { Fit between the module and the } \\
\text { curriculum }\end{array}$ & MI & MII & MIII & Mean \\
\hline fits the curriculum goals & 4 & 4 & 4 & 4 \\
\hline has appropriate linguistic content & 3.83 & 3.83 & 3.67 & 3.78 \\
\hline has appropriate thematic content & 3.83 & 3.83 & 3.83 & 3.83 \\
\hline $\begin{array}{l}\text { fits the pedagogical and SLA philosophy } \\
\text { of the program/course }\end{array}$ & 4 & 4 & 3.83 & 3.94 \\
\hline Grand Mean & 3.92 & 3.92 & 3.83 & 3.89 \\
\hline Fit between the module and the students & MI & MII & MIII & Mean \\
\hline $\begin{array}{l}\text { explanations understandable and usable } \\
\text { for students }\end{array}$ & 4 & 4 & 4 & 4 \\
\hline $\begin{array}{l}\text { examples understandable and usable for } \\
\text { students }\end{array}$ & 3.83 & 4 & 4 & 3.94 \\
\hline activities appropriate for students & 4 & 3.83 & 3.83 & 3.89 \\
\hline $\begin{array}{l}\text { thematic content understandable and } \\
\text { appropriate for students }\end{array}$ & 3.67 & 3.67 & 3.67 & 3.67 \\
\hline \multicolumn{5}{|l|}{ Grand Mean } \\
\hline $\begin{array}{c}\text { Fit between the modules and the } \\
\text { teachers }\end{array}$ & MI & MII & MII & Mean \\
\hline fits the language skills of teachers & 4 & 4 & 4 & 4 \\
\hline fits the knowledge-base of teachers & 3.83 & 3.83 & 3.83 & 3.83 \\
\hline $\begin{array}{l}\text { provides explanations that can be used } \\
\text { by teachers }\end{array}$ & 3.83 & 3.83 & 3.83 & 3.83 \\
\hline $\begin{array}{l}\text { provides examples that can be used and } \\
\text { expanded by teachers }\end{array}$ & 3.83 & 3.83 & 3.83 & 3.83 \\
\hline $\begin{array}{l}\text { provides in-book or instructor's manual } \\
\text { for teachers }\end{array}$ & 3.83 & 3.5 & 3.5 & 3.55 \\
\hline Grand Mean & 3.83 & 3.80 & 3.80 & 3.80 \\
\hline Over-all fit of the modules & MI & MII & MIII & Mean \\
\hline Should the module be selected? & 4 & 4 & 4 & 4 \\
\hline
\end{tabular}

Legend: 4- ( 3.25 - 4.0) Y (Yes) - A good fit 3- (2.5 - 3.24 ) P (Perhaps) - an adequate fit 2- (1.75 -2.49) PN (Probably not) - a poor fit $1.0-1.74$ ) AN (Absolutely not) - wrong for curriculum, students and/or teachers

For item 4 (thematic content are understandable and appropriate for the students), all the modules were rated 3.67 by the teachers. This means that the contents of the modules were understandable for the students.

The activities in language classroom should be "real" and purposeful: "With respect to teaching the methodology, it is crucial that classroom activities reflect those communication activities that the learner is most likely to engage in” [2].

Moreover, language materials should be contextualized: Instead of extracting or creating discrete pieces of language, materials must be presented in a meaningful context.

It is maintained [8] that creativity and individual learners' performance can also be attained through the presentation and performance of the material at the appropriate level and in an organized manner.

Evaluation of the Test of Fit between Modules and the Teachers. For item 1 (the module fits the language skills of the teachers), all the teachers rated it 4 for the 3 modules. The lessons could be expounded by the teachers because the lessons focused on the grammar points and the elements of technical writing. The grammar focus of Module I were the basic structures that necessitate correct sentence construction specifically those that would help students construct sentences. The grand mean for this item is 4 .
The module fitting the knowledge-base of the teachers (item 2) was rated 3.83 for all the modules. The contents of the module were within the information bank of the teachers who handle Technical Writing. Moreover, the topics in the module were required in the syllabus which the teachers use.

The modules provide explanations that can be used by the teachers (item 3) was rated 3.83 in the three modules. This means that each lesson or topic in the module is explained and is supported with examples. The explanations enrich the teacher's understanding about the topics.

The module provides examples that can be used and expanded by the teachers (item 4) was rated 3.83 in the three modules. Several examples were used as springboard for the teacher to explain the lesson and could be further integrated with incoming lessons.

To help the teachers more, an instructor's manual (item 5 ) is provided to support the teachers and this was rated 3.16 (Module I), and 3.5 each for Module II and Module III. The overall mean is 3.80 . The result shows that the necessary aid for the teachers is in the teacher's manual together with the answers to the tasks as well as supplementary activities. The teacher's guide was prepared to provide the teachers the ready answers to the tasks as well as supplementary activities that could be used by the teachers.

Table 5 also shows that the overall fit of the modules is 4 (Yes-A good fit).

The teacher in independent study or autonomous learning is a facilitator for the learning and satisfaction of the students. Monitoring and guiding the students in the process will yield a more beneficial output because when the students are left on their own, they fail to learn and even learn incorrectly.

The module is an innovation among developed and developing countries whose impact is brought by projects on the preparation and use of modules of different offices like the Asia Center of Innovations in Education Innovation. It is an instructional material which possesses the qualities that will make the individual an independent learner, self-pacing and progressing at his own rate, finally giving him the feeling of self-satisfaction, the very essence of modular instruction.

Instructional materials are important [18] since the teacher knows his students, the general teaching skill of the teacher, his willingness to prepare a wealth of instructional materials, his linguistic ability and his warm manner will, to a great extent, affect the teaching-learning situation.

\subsection{Findings of the Study}

The following were the salient findings of the study:

1. The eleven (11) technical writing needs of the students identified in this study were: a) special techniques in technical writing, b) revising weak be-verbs/sentence pattern for technical writing, c) revising noun stacks, d) revising redundant phrasing, e) constructing verbal to nonverbal data, f) writing conclusions from research findings, g) writing recommendations for research, $h$ ) differentiating opinions from facts, i) observing mechanics specifically punctuation, j) stating research problems, and k) constructing sentence which includes arranging words 
in normal order, putting main idea first, and using correct pronoun reference.

2. The modules that were developed to address the technical writing needs of the students were : 1) Module I (Overview of Technical Writing) consisting of the linguistic features and introductory technical writing concepts containing 11 regular tasks, 5 assigned tasks and 3 evaluative tasks with a total number of 19 tasks; 2) Module II (Special Techniques in Technical Writing) has 17 regular tasks, 15 assigned tasks and 6 evaluative tasks with a total number of 38 tasks; and 3) Module III (Writing the Research Paper) contains 18 regular tasks, 6 assigned tasks and 4 evaluative tasks with a total number of 28 tasks.

3. a Module II was evaluated by 2 sets of student respondents. The control group evaluated the module along subject matter (2.94), vocabulary and structures (2.99), exercises (3.11), illustrations (3.06), and physical make-up (3.07). The overall evaluation was 3.03 (Good).

3. b The experimental group gave the following rating: subject matter (3.12); vocabulary and structures (2.87); exercises (3.07); illustrations (2.84) and physical make-up (2.55); overall mean was 2.89 (Good).

3. c Module II was rated "Good" by the control (3.03) and experimental (2.89) groups.

4. a The English teachers evaluated Module I (Overview of Technical Writing) along subject matter (3.88), vocabulary and structures (3.83), exercises (3.63), illustrations (3.44) and physical make-up (3.11); overall mean for Module I was 3.58 (Excellent).

4. b Module II (Special Techniques in Technical Writing) was evaluated as follows: subject matter (3.75), vocabulary and structures (3.59), exercises (3.47), illustrations (3.22) and physical make-up (3.17). Overall mean was 3.44 (Excellent).

4. c Module III (Writing the Research Paper) was evaluated along subject matter (3.67), vocabulary and structures (3.65), exercises (3.57), illustrations (3.33) and physical make-up (3.22). Overall mean was 3.49 (Excellent). In general, the three modules were rated "Excellent" by the English teachers. Statistically, the ratings of the English teachers did not vary significantly.

4. c. 1 Evaluation of the fit of modules was conducted along 3 criteria: evaluation of fit for the curriculum, students and teachers. The English teachers evaluated Module I for curriculum 3.85, for students 3.95 and fit for the teachers 3.80., and over all fit for Module I is 4 .

4. c. 2 Module II was evaluated fit for the curriculum (3.90), fit for the students (3.90) and fit for the teachers (3.76), and over all fit was 4.

4. c. 3 Module III was evaluated fit for the curriculum (3.80), fit for the students (3.10) and fit for the teachers (3.76) and the overall fit was 4. The modules were recommended for use in Technical Writing classes.

\subsection{Conclusions}

The study was conducted to identify the technical writing needs of the students. It is imperative to account or identify some learning needs which have been overlooked which come out to the fore as a result of students' works on the module. Such needs as special techniques in technical writing, grammatical competencies and mechanical foundations of technical writing were noted.
The needs that were identified were the basis in the development of the modules.

To address the needs, three modules that contained lessons and exercises to enhance the writing ability of the students were developed. Lessons or tasks will be prepared to address the needs of the students. Module I (Overview of Technical Writing) covers the linguistic requirements for technical writing. Module II (Special Techniques in Technical Writing) presents the practical guide and techniques used in technical writing, and Module III (Writing the Research Paper) provides the handy information and tips for research writing. The regular, assigned and evaluative tasks which the teacher could choose from complete each module.

Moreover, the study looked into the difference of the of the evaluation of Module II by the control and experimental groups. In improving the modules, the evaluation of students is helpful in the improvement of the materials. The language as well as the arrangement of activities or tasks may take into account the level of difficulty as well as the practical application of the concepts presented in the modules. The evaluation along subject matter, vocabulary and structures, exercises, illustrations, and physical make-up yield an overall evaluation which was Good. The evaluation results suggest the modules were developed in accordance with the principles of instructional materials development.

Experts' evaluation of the modules contributed to the improvement of the modules because the comments and suggestions from the English teachers were incorporated. The results show that the three modules were rated Excellent. As to the evaluation of fit of the modules for the curriculum, teachers and students, the modules were evaluated fit. The modules were supportive to the implementation of the curriculum and were within the control of the teachers. The students could use them, and the modules were recommended for use in Technical Writing class.

\subsection{Recommendations}

Based on the results and conclusions of the study, the following recommendations are promulgated:

1. Needs analysis is a continuous process. It is imperative to account or identify some learning needs which have been overlooked which come out to the fore as a result of students' works on the module.

2. Since evaluation of students is important, their responses and performance become a basis for the refinement of the materials. Activities/tasks may be added/modified to enrich or improve student written output.

3. With regard to the evaluation of the regular, assigned and evaluative tasks, it is highly recommended that these tasks be reviewed to improve the modules. Emphasis be given to assigned tasks since student output depends on how well these tasks are to be done and that students are on their own and with no teacher supervision. Of primordial importance is the evaluative tasks. As recommended by the evaluators, there is a need to test student knowledge and application of skills in a variety of ways like paragraph development, one-on-one questioning of students, questionnaire to measure how well the students has improved his values, among others. 
4. Although the modules were rated "Excellent" by the English teachers, the comments and suggestions of the evaluators should be taken into account. Suggestions like providing illustrations for most of the inputs, inclusion of interpretation of results as part of research paper writing and using similar fonts for all entries are to be integrated to improve the content of the modules.

5. The modules are suggested to be used by Technical Writing classes to effect autonomous learning among the students.

6. Other researches on development and evaluation of Technical Writing modules may be conducted to validate the findings of the current study.

\section{References}

[1] Aliweng, D. Writing proficiency level of freshmen students at Baguio School of Business Technology (BSBT) College. Unpublished Master's Thesis, Benguet State University, La Trinidad, Benguet. 2008.

[2] Canale, M. and M. Swain. Theoretical Bases of Communicative Approaches to Second Language Teaching and Testing: Washington DC. TESOL. 1980.

[3] Cruickshank, D. et al. The Act of Teaching. Third Edition. 1221 Avenue of the Americas, New York, NY. McGraw Hill Companies. 2003.

[4] Emotin-Bucjan, M. Development and Validation of Modules in English 2: Writing in the Discipline. Unpublished Thesis. Surigao del Sur State University, Tandag Campus. 2011.

[5] Hutchinson, T., and A. Waters. English for specific purposes: A learning-centered approach. Cambridge: Cambridge University Press. 1987.

[6] Hufana, E.R. Rationale for Task-based Materials. Think Journal of the Baguio Colleges Foundation. 1996.
[7] Lepetit and Cichocki. Teaching Languages to Future Health Professionals: A Needs Assessment Study. The Modern Language Journal. Vol. 86, Issue \#3. April. 2003.

[8] March, 2001. Language Learning. A journal of Research in Language Studies. Onlinelibrary.wiley.com.

[9] Msanjila, Y.P. Problems of teaching through the medium of Kiswahili in teacher training colleges in Tanzania, Multilingual and Multicultural Development. 11 (4).

[10] Murcia, M. Teaching English as a Second Language, Third Edition. Heile and Heinle, Thomson Learning, Asia, Singapore. 2006.

[11] Nunan, D. The Learner-Centered Curriculum. Cambridge. Cambridge University Press. In Benson, P. and P. Voller (Eds.). 1988.

[12] Nunan, D. Designing tasks for the communicative classroom. UK Cambridge University Press. 1989.

[13] Persky, H. M. Daane, and Y. Jin. The Nation's Report Card: Writing 2002. U.S. Department of Education, National Center for Education Statistics. 2003.

[14] Richteric, R. et al. Id Identifying the Needs of Adults Learning a Foreign Language. Downloaded article. August 1, 2012. 1978.

[15] Rothwell, W. et al. Mastering the Instructional Design Process. Jossey-Bass., Publishers, 350 Sansome Street, San Francisco, California. 1998.

[16] Trioa, G.A. and Graham, S. Effective writing instructions across the grades: What educational consultant should know, Journal of Educational and Psychological Consultation. 14: 75-89. 2003.

[17] Tullay, R. B. Language Materials Development for the Multiple Intelligences of BSU Freshman Education Students. Unpublished Dissertation, Saint Louis University, Baguio City. 2010.

[18] Valdez, A. Development and Validation of Multiple IntelligencesBased Instructional Material in Intermediate Algebra. Unpublished Master's Thesis. Philippine Normal University, Taft Avenue, Manila. 2006.

[19] Waguey, L. Effectiveness of Task-Based Instructional Materials in Developing Writing Skills of BS Fisheries Freshmen. Unpublished Dissertation. Benguet State University. 2012.

[20] White, R. and Arndt, V. Process Writing. London: Longman. 1991.

[21] WRIGHT. English Is Power. Manila Bulletin. 2009. 